\section{Where is the outrage? The abandonment of long- established public health travel clinics in Saskatchewan}

Dear Editor:

Re: Guyon A, Hancock T, Kirk M, MacDonald M, Neudorf C, Sutcliffe P, et al. The weakening of public health: A threat to population health and health care system sustainability. Can $J$ Public Health 2017;108(1):e1-e6. doi: 10.17269/CJPH.108.6143

For those of us who have been through the experience of chronic public health reforms in Canada over the past three decades, there is real fear that provincial governments will go too far in undermining our core capacity to protect the health of our citizens. This has been voiced by Guyon and colleagues, ${ }^{1}$ who point out the dangers of limiting the scope of practice of local public health units, among other concerns. One disturbing example is the Saskatchewan government's recent and abrupt directive to the public health sector to transition all its established travel clinics within one year to the private for-profit sector, which is not yet prepared to deliver this same service. ${ }^{2}$ Public health travel nurses in that province have provided this preventive service on a revenue-neutral basis for many years, meaning there will be no cost savings to the government by cutting it. Saskatchewan's longstanding travel health services employ 15 dedicated public health nursing positions, according to its Assistant Deputy Minister, ${ }^{2}$ which represents significant local capacity that could be engaged toward improving the Province's international communicable disease control (CDC) function, especially in the larger centres of Regina and Saskatoon.

We forget our own history when we allow the denuding of our public health sector of its international CDC capabilities at the local level without a fight. In 1848, the first modern public health legislation was enacted, primarily as a response to a series of cholera outbreaks sweeping across the United Kingdom, Europe, and North America as a result of international travel. ${ }^{3}$ The revision in 1875 of this "Act for promoting the Public Health" became the template for development of all future commonwealth public health organizations, including those in Canada. In 1851, the first of the International Sanitary Conventions set up an ongoing process for developing coordinated international public health, the Pan-American Health Organization (PAHO), and eventually the World Health Organization (WHO) overseeing the International Health Regulations (IHR). ${ }^{4}$ The importation of SARS to Ontario in 2003, with the related poorly coordinated multi-level responses, led to the creation of the Public Health Agency of Canada (PHAC) in $2004 .^{5}$
Many major milestones in the creation and evolution of Canada's public health sector were triggered by travel-related events. Moreover, the recent revision of the IHR in 2005 has also expanded obligations of countries such as Canada. The fourth core requirement states the need for local public health capacity to develop timely surveillance and emergency response. The International Certificate of Vaccination and Prophylaxis (ICVP) has been expanded from solely pertaining to yellow fever immunization to an infinite potential of temporary or permanent certificate requirements for any "public health emergency of international concern" or PHEIC issued by the WHO. This has recently included temporary certificate recommendations against the spread of poliovirus. ${ }^{6}$ Issuing ICVPs for current and future additional diseases requires competency and connectedness within all levels of Canada's public health sector. Selling off travel clinic capabilities undermines this effort of public health officials to detect and protect the local population from imported threats. Where is the outrage and support for Saskatchewan's public health travel nurses?

Rudolf A. Zimmer, MD, FCFP, FRCPC, CTropMed(R)

Travel Medicine Consultant, AHS Calgary Zone, Calgary, AB HIV PEP Medical Consultant, AHS Calgary Zone, Calgary, AB Odyssey Travel + Tropical Medicine clinician, Calgary, AB

E-mail: rzimmer@ucalgary.ca

doi: $10.17269 / \mathrm{CJPH} .108 .6339$

\section{REFERENCES}

1. Guyon A, Hancock T, Kirk M, MacDonald M, Neudorf C, Sutcliffe P, et al. The weakening of public health: A threat to population health and health care system sustainability. Can J Public Health 2017;108(1):e1-e6. PMID: 28425892. doi: 10.17269/cjph.108.6143.

2. Cowan P. Travel immunization clinics will maintain status quo for up to a year: Until details are mapped out, residents will continue to get their travel vaccinations at public health offices in Saskatchewan. Regina Leader-Post, April 20, 2017. Available at: http://leaderpost.com/news/local-news/travelimmunization-clinics-will-maintain-status-quo-for-up-to-a-year (Accessed May 27, 2017).

3. Fee E, Brown TM. The Public Health Act of 1848. Bull World Health Organ 2005; 83(11):866-67. PMID: 16302044. doi: 10.1590/S0042-96862005001100017.

4. Fidler DP. From International Sanitary Conventions to global health security: The new International Health Regulations. Chin J Int Law 2005;4(2):325-92. doi: 10.1093/chinesejil/jmi029.

5. Mowat DL, Butler-Jones D. Public health in Canada: A difficult history. Healthc Pap 2007;7(3):31-36. PMID: 17476126. doi: 10.12927/hcpap..18755.

6. Public Health Agency of Canada. Recommendations for Completing the International Certificate of Vaccination or Prophylaxis for Poliovirus Vaccination. Ottawa, ON: Public Health Agency of Canada, 2014. Available at: http://www. phac-aspc.gc.ca/tmp-pmv/yf-fj/designation/recomm-eng.php (Accessed May 27, 2017). 